\title{
Nuclear and Cytoplasmic Localization of Basic Fibroblast Growth Factor in Astrocytes and CA2 Hippocampal Neurons
}

\author{
William R. Woodward, ${ }^{1}$ Rae Nishi, ${ }^{2}$ Charles K. Meshul, ${ }^{3}$ Tracey E. Williams,, ${ }^{1}$ Margaret Coulombe, ${ }^{2}$ and \\ Felix P. Eckenstein ${ }^{2}$ \\ 'Departments of Neurology and ${ }^{2} \mathrm{Cell}$ Biology and Anatomy, and the ${ }^{3}$ Veterans Affairs Medical Center, Oregon Health \\ Sciences University, Portland Oregon 97201
}

\begin{abstract}
Fibroblast growth factors (FGFs) are known to stimulate mitogenesis in a variety of non-neuronal cell types and to support the survival in vitro of many neuronal cell types. The physiological role of FGFs in the CNS is currently not known. The present study determined the distribution in the rat CNS of a prominent member of the FGF family, basic FGF (bFGF). Immunohistochemical analysis showed that bFGF immunoreactivity was found predominantly in astrocytes throughout all regions of the CNS. In contrast, only a few neuronal populations were found to contain bFGF immunoreactivity, most prominent among them, neurons in the CA2 area of the hippocampus. This predominant localization of bFGF to astrocytes was confirmed by two other observations: (1) highly enriched cultures of astrocytes contained bFGF immunoreactivity and bioactivity, whereas highly enriched cultures of cerebral cortical neurons contained no detectable bFGF, and (2) neonatal rat cerebral cortex, which contains only a few differentiated astrocytes, also contained no detectable bFGF immunoreactivity and only low amounts of bFGF bioactivity. Immunocytochemical analysis also suggested that bFGF immunoreactivity was present in the nucleus as well as the cytoplasm of astrocytes and CA2 neurons. This nuclear localization was confirmed by EM analysis of the intracellular distribution of the immunoperoxidase reaction product. In addition, preparations of both nuclear and soluble fractions of brain extracts contained bFGF immunoreactivity and bioactivity. These data suggest that bFGF might be involved in mediating astrocytic influences on the late postnatal maturation and plasticity in the CNS, and that the nuclear localization of bFGF within astrocytes may play an important role in the differentiation of these cells. In addition, bFGF may play a similar role in a few specific neuronal populations, such as CA2 hippocampal neurons.
\end{abstract}

Fibroblast growth factors (FGFs) are members of the family of heparin-binding polypeptide growth factors that stimulate mitogenesis in a wide variety of cell types. The best-studied mem-

Received Apr. 29, 1991; revised Aug. 14, 1991; accepted Aug. 16, 1991

We are grateful to $T$. Holbert for technical assistance. This work was supported by NIH Grants AG07424, NS1 7493 (F.P.E.), and NS25767 (R.N.) and by a March of Dimes Basil O'Connor grant (F.P.E.), a Department of Veterans Affairs Merit Award (C.K.M.), and a grant from the Medical Research Foundation of Oregon (W.R.W.).

Correspondence should be addressed to Felix P. Eckenstein, Department of Cell Biology and Anatomy, Oregon Health Sciences University, 3181 SW Sam Jackson Park Road, Portland, OR 97201.

Copyright (c) 1992 Society for Neuroscience $0270-6474 / 92 / 120142-11 \$ 05.00 / 0$ bers of the FGF family are acidic FGF (aFGF) and basic FGF (bFGF; see Burgess and Maciag, 1989, for review), but additional members of this family [HST (Taira et al., 1987), Int-2 (Moore et al., 1986), FGF-5 (Zhan et al., 1988), FGF-6 (Marics et al., 1989), and KGF (Marchese et al., 1990)] have been identified. The members in this family show structural homology and appear to share the properties of stimulating mitogenesis and binding to heparin with high affinity.

Recent observations suggest that FGFs may be of importance for the development and maintenance of nervous tissue. FGFs are present in relatively high levels in brain (Gospodarowicz et al., 1987; Burgess and Maciag, 1989), with aFGF and bFGF possibly being the main mitogenic factors extractcd from adult brain (Thomas, 1987). Reported actions of FGFs in vitro include stimulation of mitogenesis in astrocytes (Pettmann et al., 1985), oligodendrocytes (Eccleston and Silberberg, 1985), and Schwann cells (Davis and Stroobant, 1990); promotion of fiber outgrowth in both PC-12 cells (Wagner and D'Amore, 1986) and adrenal chromaffin cells (Stemple et al., 1988); and promotion of survival or fiber outgrowth of neurons dissociated from cerebral cortex (Morrison et al., 1986), hippocampus (Walicke et al., 1986), retina (Lipton et al., 1988), cerebellum (Hatten et al., 1988), the septal area (Grothe et al., 1989), the ciliary ganglion (Schubert et al., 1987; Unsicker et al., 1987; Eckenstein et al., 1990), and sympathetic and sensory ganglia (Eckenstein et al., 1990).

The physiological relevance of these in vitro observations to the functions of aFGF and bFGF in vivo are not well understood for the following reasons. (1) Some of the in vitro effects of FGFs, such as the stimulation of mitogenesis of astrocytes, are not observed in the normal CNS, in spite of the fact that the CNS contains substantial levels of FGFs. (2) aFGF and bFGF may not be localized to an intracellular secretory pathway as they appear to lack a signal peptide sequence (Burgess and Maciag, 1989), a feature that is generally thought to be necessary for the efficient secretion of polypeptides (Walter and Lingappa, 1986); indeed, some fraction of total cellular FGF appears to be localized to the nucleus of cells that were transfected in vitro with FGF expression vectors (Renko et al., 1990). (3) The pleiotrophic effects of the FGFs observed in vitro seem somewhat nonspecific considering the very specific cellular interactions that guide CNS development and maintenance. This apparent discrepancy between the abundant FGF effects observed in vitro and the possibly more restricted role these factors may play in vivo could be explained by the hypothesis that FGFs become available to responsive cells in vivo only at restricted times and locations. 
As a first step toward testing this hypothesis, it is necessary to determine the patterns of expression of FGFs in the nervous system, as well as to identify the cell types expressing FGFs in this tissue and to investigate whether nuclear localization of FGFs may not only be observed in transfection systems but also in normal cells in vivo. We earlier demonstrated that aFGF and bFGF show a differential distribution in grossly dissected areas of the nervous system (Eckenstein et al., 1991a), supporting the hypothesis that specific FGFs may be expressed in restricted locations. The present study uses both light- and clectron-microscopic immunohistochemical localization of bFGF, in combination with biochemical and bioassay methods, to determine the cellular and ultrastructural localization of bFGF in the rat CNS.

Some of the data reported here have been presented in short form at a recent conference (Eckenstein et al., 1991b).

\section{Materials and Methods}

Immunohistochemistry. Newborn and adult female Sprague-Dawley rats were anesthetized and perfused through the heart as follows: adults were first perfused with $50 \mathrm{ml}$ of $100 \mathrm{~mm}$ sodium phosphate, $\mathrm{pH} 7.2$, followed by $300 \mathrm{ml}$ of $5 \%(\mathrm{v} / \mathrm{v})$ formalin in the same buffer; newborns were perfused with $5 \mathrm{ml}$ of $5 \%$ formalin in buffer only. Tissues were then dissected and postfixed in 5\% buffered formalin for $1 \mathrm{hr}$ at room temperature and sunk in $30 \%$ sucrose, $100 \mathrm{~mm}$ sodium phosphate, $\mathrm{pH} 7.2$, and serial $50-\mu \mathrm{m}$-thick frozen sections were prepared, spanning from olfactory bulb to cervical spinal cord.

Sections were first incubated for $2 \mathrm{hr}$ in $100 \mathrm{~mm}$ Tris buffer, $\mathrm{pH} 7.8$, containing $150 \mathrm{~mm} \mathrm{NaCl}, 0.5 \%$ Triton $\mathrm{X}-100,10 \%$ horse serum, and $0.05 \%$ sodium azide (Buffer $\mathrm{A}$ ), followed by overnight incubation in one of the following primary antibodies diluted in Buffer A: mouse monoclonal anti-bFGF, ascites fluid 3386 (a generous gift from Dr. C. Hart, Zymogenetics) diluted 1:10,000; mouse monoclonal anti-glial fibrillary acidic protein (anti-GFAP) (Boehringer), $2 \mu \mathrm{g} / \mathrm{ml}$; or mouse control ascites (Sigma), diluted 1:2000). Sections were then washed and incubated for $1 \mathrm{hr}$ in biotinylated anti-mouse antibodies (diluted 1:100 in Buffer A; Vector), washed, incubated for $1 \mathrm{hr}$ in an avidin-peroxidase complex (Vector, prepared as suggested by the manufacturer), washed, and reacted for $10 \mathrm{~min}$ with diaminobenzidine $(1 \mathrm{mg} / \mathrm{ml})$ and $0.03 \%$ hydrogen peroxide in phosphate-buffered saline. The stained sections were mounted and coverslipped according to standard procedures. The mouse monoclonal antibody to bFGF was preadsorbed with $1 \mu \mathrm{g} / \mathrm{ml}$ of human recombinant bFGF in experiments designed to ascertain the specificity of bFGF label observed.

For electron microscopic localization of bFGF immunoreactivity, tissue was prepared as described above, except that vibratome sections were used instead of frozen sections, and the concentration of Triton $\mathrm{X}-100$ in Buffer $\mathrm{A}$ was reduced to $0.2 \%$. Stained sections were then reacted for $1 \mathrm{hr}$ with $1 \%$ osmium tetroxide in $100 \mathrm{~mm}$ cacodylate buffer,

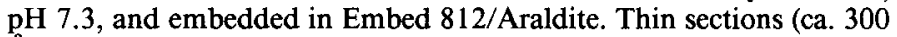
$\AA$ thick) were cut and examined on a JEOL TEMSCAN transmission electron microscope. Cells were identified as astrocytes by the presence of glial filaments and rosettes of free ribosomes; neurons were identified by the presence of abundant cytoplasm with long segments of rough endoplasmic reticulum.

Double immunofluorescent localization of $b F G F$ and GFAP was performed by simultaneously incubating sections in the mouse monoclonal antibody (see above) and a rabbit antiserum to GFAP (diluted 1:500; a gift of Dr. G. Nilaver), followed by incubation in fluorescein-labeled goat anti-mouse and rhodamine-labeled goat anti-rabbit antibodies (diluted 1:100; Cappel). Nuclei were labeled in these sections by incubation for $5 \mathrm{~min}$ in fluorescent Hoechst dye $33528(1 \mu \mathrm{g} / \mathrm{ml})$. The resulting green, red, and blue immunofluorescent labels were analyzed in a Zeiss epifluorescence microscope using narrow-band filters. Control mouse ascites fluid and rabbit nonimmune serum were substituted for the primary antibodies in order to ascertain the specificity of staining observed.

Cultures of cortical astrocytes and neurons were immersion fixed in $5 \%$ buffered formalin and stained for bFGF, GFAP, and neurofilament (antibody RT 97, ascites, diluted 1:2000; Developmental Hybridoma
Bank; see Wood and Anderton, 1981) immunoreactivity using methods identical to those described above for the staining of tissue sections.

Preparation of tissue extracts and supernatants. Adult female SpragueDawley rats and newborn rat pups were killed by asphyxiation with carbon dioxide, and tissues were dissected, frozen immediately, and stored at $-70^{\circ} \mathrm{C}$ for no longer than $14 \mathrm{~d}$. Tissues were thawed and quickly homogenized in $10 \mathrm{ml} / \mathrm{gm}$ of ice-cold $20 \mathrm{~mm}$ Tris, $\mathrm{pH} 8.2$, containing $600 \mathrm{~mm} \mathrm{NaCl}$. This concentration of $\mathrm{NaCl}$ was found in pilot experiments to be sufficient to extract all membrane-bound bFGF. The homogenates were centrifuged for $10 \mathrm{~min}$ at $15,000 \times \mathrm{g}$, supernatants were collected, and bFGF was determined by Western blot analysis and bioassay as described below. Protein concentration in supernatants was determined using a Coomassie blue binding assay (Bio$\mathrm{Rad})$. Tissues from at least three different animals were assayed for all data presented in this study.

Preparation of nuclear pellets and supernatants. The forebrain from adult rats was homogenized in $10 \mathrm{ml} / \mathrm{gm}$ of cold $20 \mathrm{~mm}$ Tris, $\mathrm{pH} 8.2$, containing $1 \%(\mathrm{w} / \mathrm{v})$ CHAPS and $300 \mathrm{~mm}$ sucrose. The homogenate was passed through two layers of lens paper and centrifuged for $10 \mathrm{~min}$ at $800 \times g$. The supernatant was carefully removed from the pellet and dialyzed against $20 \mathrm{~mm}$ Tris, pH 8.2 , containing $600 \mathrm{~mm} \mathrm{NaCl}$. The pellet was extracted with $2 \mathrm{M} \mathrm{NaCl}$ in $20 \mathrm{~mm}$ Tris, $\mathrm{pH} 8.2(5 \mathrm{ml} / \mathrm{gm}$ starting tissue weight), and centrifuged for $20 \mathrm{~min}$ at $20,000 \times \mathrm{g}$, and the supernatant was dialyzed as above. Protein (see above) and DNA concentrations (Labarca and Paigen, 1980) were quantified in these fractions, and the presence of bFGF was determined by Western blot analysis and bioassay as described below.

Preparation of tissue cultures. Astrocyte cultures were prepared in a manner similar to that described by McCarthy and deVellis (1980). Briefly, cerebral cortices from postnatal day 2 rat pups were removed, cleaned of meninges and blood vessels, and gently minced. The pieces of tissue were enzymatically dissociated by incubation in $0.2 \%(\mathrm{w} / \mathrm{v})$ trypsin at $37^{\circ} \mathrm{C}$ for $25 \mathrm{~min}$ and then dispersed mechanically by trituration. Undissociated tissue and cell clumps were removed by passing the cell suspension through $130 \mu \mathrm{m}$ and $15 \mu \mathrm{m}$ Nitex filters. Cells were plated on tissue culture dishes (10 cm diameter, $10^{7}$ cells per dish) in modified Leibowitz L-15 medium containing bicarbonate, $10 \%(\mathrm{v} / \mathrm{v})$ fetal bovine serum, penicillin, streptomycin, glutamine, and $6 \mathrm{mg} / \mathrm{ml}$ glucose. Cells were grown close to confluence, and then the medium was changed to minimum essential medium (MEM), containing N2 supplement (Bottenstein and Sato, 1979), and the cultures were grown in this serum-free medium for an additional $7 \mathrm{~d}$.

Neuronal cultures from postnatal rat cortex were prepared as previously described (Huettner and Baughman, 1986). Cortical hemispheres from neonatal rat pups were cleaned of meninges and blood vessels, dissected, and dissociated by incubation in $20 \mathrm{U} / \mathrm{ml}$ papain at $37^{\circ} \mathrm{C}$ for $20 \mathrm{~min}$, followed by gentle trituration. The cell suspension was passed through a $130 \mu \mathrm{m}$ Nitex filter to remove clumped cells, and the dissociated cells were plated on tissue culture dishes $(10 \mathrm{~cm}$ diameter, 5 $\times 10^{7}$ cells per dish) in MEM containing N2 supplement, $2 \times 10^{-5} \mathrm{M}$ fluorodeoxyuridine, $2 \times 10^{-5} \mathrm{M}$ uridine, and $10 \% \mathrm{MEM}$-based astrocyteconditioned medium.

The purity of the different cell type-specific cultures was determined by immunohistochemical localization of GFAP and ncurofilament immunoreactivity by the methods described above.

Confluent astrocyte and 6-d-old neuronal cultures were homogenized in $20 \mathrm{~mm}$ Tris, pH 7.2, containing $600 \mathrm{~mm} \mathrm{NaCl}, 1 \%$ Chaps, $5 \mathrm{~mm}$ EDTA ( $1 \mathrm{ml}$ per plate) and dialyzed against $20 \mathrm{~mm}$ Tris, pH 7.2, 600 $\mathrm{mM} \mathrm{NaCl}$. Western blot analysis and bioassay were used to determine bFGF in the dialysate as described below.

Bioassay. The total amount of mitogenic activity present in tissue and cell culture extracts was determined using a serum-free ${ }^{3} \mathrm{H}$-thymidine incorporation assay described earlier (Shipley, 1986; Eckenstein et al., 1991 a). Briefly, AKR-2B cells were transferred into 24-well culture plates $(10,000$ cells per well) in McCoy's 5A medium supplemented with $5 \%(\mathrm{v} / \mathrm{v})$ fetal bovine serum and incubated for $5 \mathrm{~d}$, by which time the cells formed a confluent monolayer. The cells were incubated for an additional $2 \mathrm{~d}$ in serum-free MCDB 402 medium (Shipley and Ham, 1981). Fresh MCDB 402, supplemented with varying concentrations of bFGF or cell or tissue extracts, was then added, and $22 \mathrm{hr}$ later the cultures were pulsed with $1.0 \mu \mathrm{Ci}$ of ${ }^{3} \mathrm{H}$-thymidine for $1 \mathrm{hr}$. The relative incorporation of ${ }^{3} \mathrm{H}$-thymidine into cold $10 \%$ trichloracetic acid-insoluble material was then determined. Total mitogenic activity in extracts was determined from dose-response curves for the extracts. One unit of mitogenic activity was defined as the amount that yields half-maximal stimulation per milliliter of assay medium. 

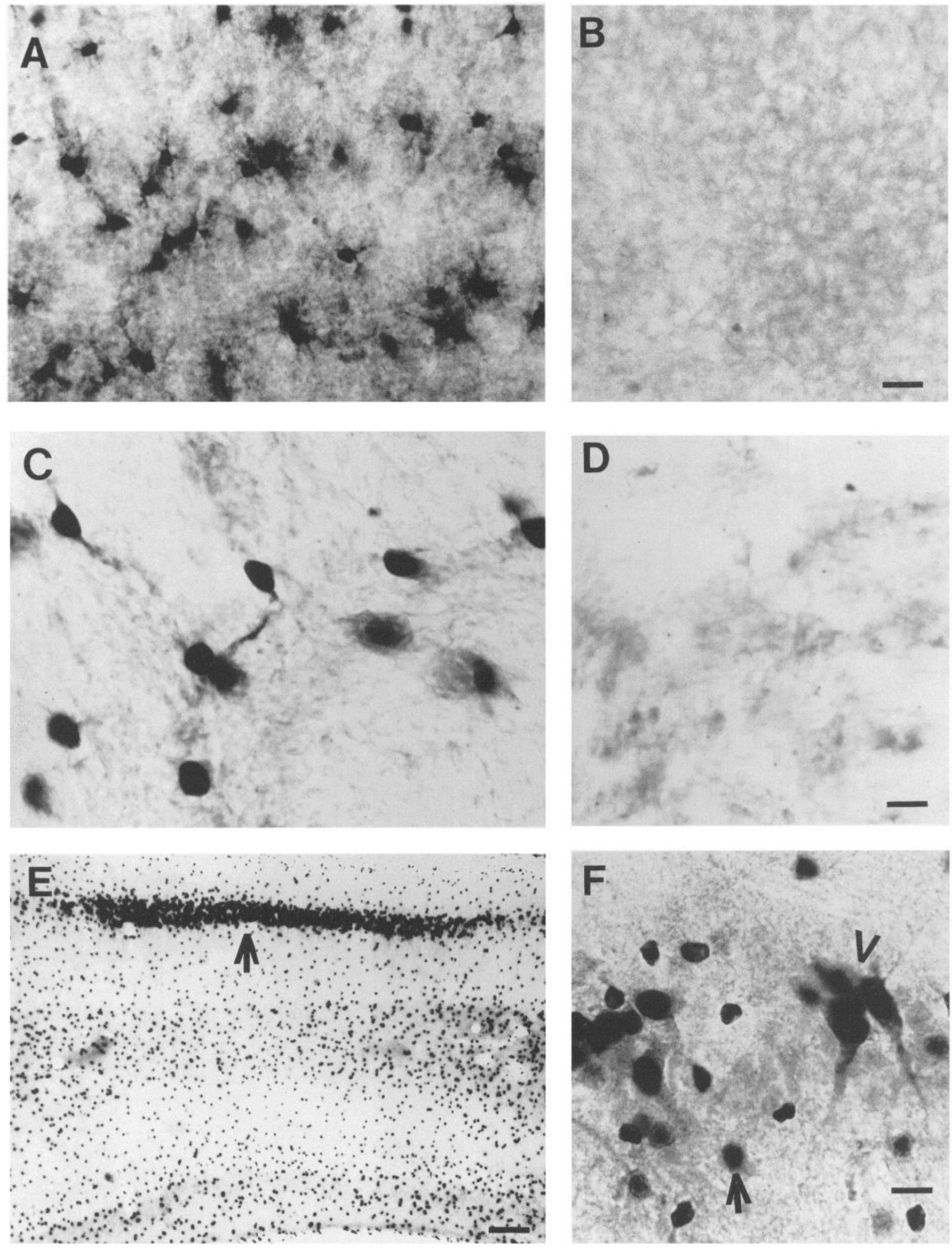
Table 1. The number of bFGF-positive neurons and astrocytes in CA1 and CA2 of hippocampus

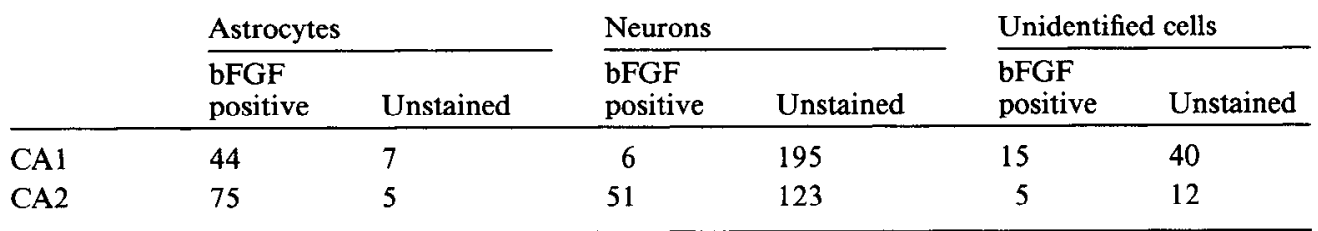

The numbers of bFGF-positive and -negative neurons and astrocytes were counted in thin sections prepared from blocks of similar size from indicated areas of adult rat hippocampus. Cell types were classified as described in Materials and Methods. Note that, in good agreement with light microscopic observations, labeled neurons are mostly confined to area CA2. In addition, the vast majority of labeled neurons had irregularly shaped nuclei, whereas unstained neurons in CA2 had nuclei of more regular shape (see Fig. 3).

This assay detects not only bFGF, but also several other mitogenic growth factors (Shipley, 1986); therefore, the amount of bFGF in extracts was determined as the difference between total mitogenic activity and that remaining after indirect immunoprecipitation of bFGF from extracts by a monoclonal antibody (3386; same as used for immunohistochemistry). The immunoprecipitation procedure was as follows: 0.5 $\mu \mathrm{l}$ of 3386 ascites and $500 \mu \mathrm{l}$ of sample were incubated for $2 \mathrm{hr}, 10 \mu \mathrm{l}$ of rabbit anti-mouse antibodies $(2 \mathrm{mg} / \mathrm{ml})$ were added and incubated for $1 \mathrm{hr}$, and $100 \mu \mathrm{l}$ of Staphylococcus aureus cell walls (from Calbiochem) were added and incubated for $30 \mathrm{~min}$. The mixturc was centrifuged, and the amount of mitogenic activity remaining in the supernatants was quantified using the AKR-2B cell assay. Nonspecific immunoprecipitation controls were performed by substituting control ascites for 3386 ascites. All precipitation steps were carried out at $4^{\circ} \mathrm{C}$.

Western blot analysis. Supernatants from cell and tissue extracts were prepared as described above, diluted with water to $300 \mathrm{~mm} \mathrm{NaCl}$, and applied onto small heparin-agarose columns ( $0.5 \mathrm{ml}$ vol; from Bio-Rad). Next, the columns were washed with $20 \mathrm{~mm}$ Tris, $\mathrm{pH} 8.2$, and then eluted with $0.5 \mathrm{ml}$ of $0.4 \%$ sodium dodecyl sulfate (SDS) at $50^{\circ} \mathrm{C}$. This protocol allows the roughly quantitative recovery of FGFs in the column eluates (Eckenstein et al., 1991a,b). The column eluates were concentrated to $50 \mu \mathrm{l}$ using a Speedvac apparatus. The eluates, and pure aFGF (a gift from Dr. K. Thomas, Merck) and bFGF (a gift from Dr. C. Hart, Zymogenetics) as standards, were separated electrophoretically in a $16 \%$ polyacrylamide gel in the presence of SDS following standard methods (Laemmli, 1970). Proteins in the gel were electroblotted onto nitrocellulose, followed by immunochemical detection of transferred bFGF. The detection protocol consisted of incubating the nitrocellulose with antibodies specific for bFGF (mouse monoclonal antibody 3386, 1: 10,000 dilution of ascites), followed by incubation with biotinylated secondary antibodies and by a routine avidin/alkaline phosphatase staining procedure (from Bethesda Research Laboratories).

\section{Results}

Immunohistochemical analysis of $b F G F$ distribution. We previously described a mouse monoclonal antibody that specifically recognized bFGF on Western blots (Eckenstein et al., 1991a). This same antibody was found to be useful for immunohistochemical localization of bFGF in 5\% formalin-fixed adult rat CNS. Pilot studies revealed that fixatives stronger than $5 \%$ formalin, especially those containing glutaraldehyde (as little as $0.1 \%$ was tested), substantially reduced or abolished staining. Throughout adult rat CNS, bFGF immunoreactivity was found predominantly in small $(<10 \mu \mathrm{m})$ cells, some of which possessed lightly stained processes (Fig. $1 A, C$ ). Double immunofluorescent localization of bFGF and GFAP demonstrated that these small cells were astrocytes (Fig. 2). Distinct bFGF immunoreactivity in neurons was found in only two areas of the CNS: pyramidal neurons in the CA2 region of hippocampus (Fig. $1 E, F)$ and neurons in retrosplenial areas of the cerebral cortex (not shown). In contrast to the reproducibly strong bFGF immunoreactivity observed in astrocytes of adult cerebral cortex, no detectable bFGF immunoreactivity was found in the cortex of neonatal rats (Fig. $1 A, B$ ). Finally, bFGF immunoreactivity was also observed in non-neuronal cells lining the ventricles (not shown). All the bFGF staining described here was abolished by preincubation of the monoclonal antibody solution with 1 $\mu \mathrm{g} / \mathrm{ml}$ of recombinant bFGF (Fig. 1D).

The intracellular distribution of bFGF immunoreactivity in labeled cells had an uneven appearance, with lighter labeling of putative cytoplasmic areas and more intense labeling of putative nuclear areas (Figs. $1 F, 2 A$ ). Thus, the cellular and ultrastructural distribution of bFGF immunoreactivity (as indicated by the peroxidase reaction product) in hippocampus was analyzed by electron microscopy. Confirming the light microscopic observations, bFGF immunoreactivity was found in astrocytes throughout the hippocampus and in neurons largely confined to the CA2 region (Table 1, Fig. 3). Interestingly, stained neurons in CA2 had a morphology somewhat different from unlabeled neurons in that same area (Fig. $3 B$ ), suggesting that a specific subpopulation of CA2 neurons contains bFGF immunoreactivity. Strong bFGF label was observed in the nuclei of both astrocytes and CA2 hippocampal neurons, and definitive staining was also seen in the cytoplasm of the labeled neurons (Fig. 3). The poor ultrastructural preservation of the tissue, caused by the weak fixation necessary to obtain acceptable bFGF staining intensity, did not allow the unambiguous demonstration of bFGF immunoreactivity in the cytoplasm of astrocytes. Nevertheless, since distinct labeling was observed of astrocytic processes in the light microscope (Figs. $1 A, C ; 2 A$ ), we conclude that bFGF immunoreactivity is present in both cytoplasmic and the nuclear compartments of astrocytes and CA2 hippocampal neurons.

Highly enriched cultures of cortical astrocytes and neurons

\section{$\longleftarrow$}

Figure 1. Localization of bFGF immunoreactivity in coronal sections of the rat CNS. bFGF immunoreactivity was localized using a monoclonal antibody to bFGF and an immunoperoxidase method. $A$, In adult neocortex, many small ( $>10 \mu \mathrm{m}$ diameter), evenly distributed cells with fine processes are stained. $B$, No specific staining is observed in neonatal neocortex. $C$, Numerous stained small-diameter cell bodies are also found in white matter, such as the external capsule. $D$. Preadsorption of the monoclonal antibody to $\mathrm{bFGF}$ with $1 \mu \mathrm{g} / \mathrm{ml}$ of recombinant $\mathrm{bFGF}$ abolishes all specific staining. External capsule is shown, from a section adjacent to the one shown in $C$. E. Large neurons are stained in hippocampal area $\mathrm{CA} 2$ but not in adjacent hippocampus (arrow points to the center of area CA2). $F$, The labcled neurons in CA2 (arrowhead) are easily distinguished from the ubiquitous small cell bodies (arrow). Note that putative nuclear structures are more heavily stained than cytoplasmic areas of labeled cells. Scale bars: $B$ (also for $A$ ), $18 \mu \mathrm{m} ; D$ (also for $C$ ), $8 \mu \mathrm{m} ; E, 120 \mu \mathrm{m} ; F, 12 \mu \mathrm{m}$. 

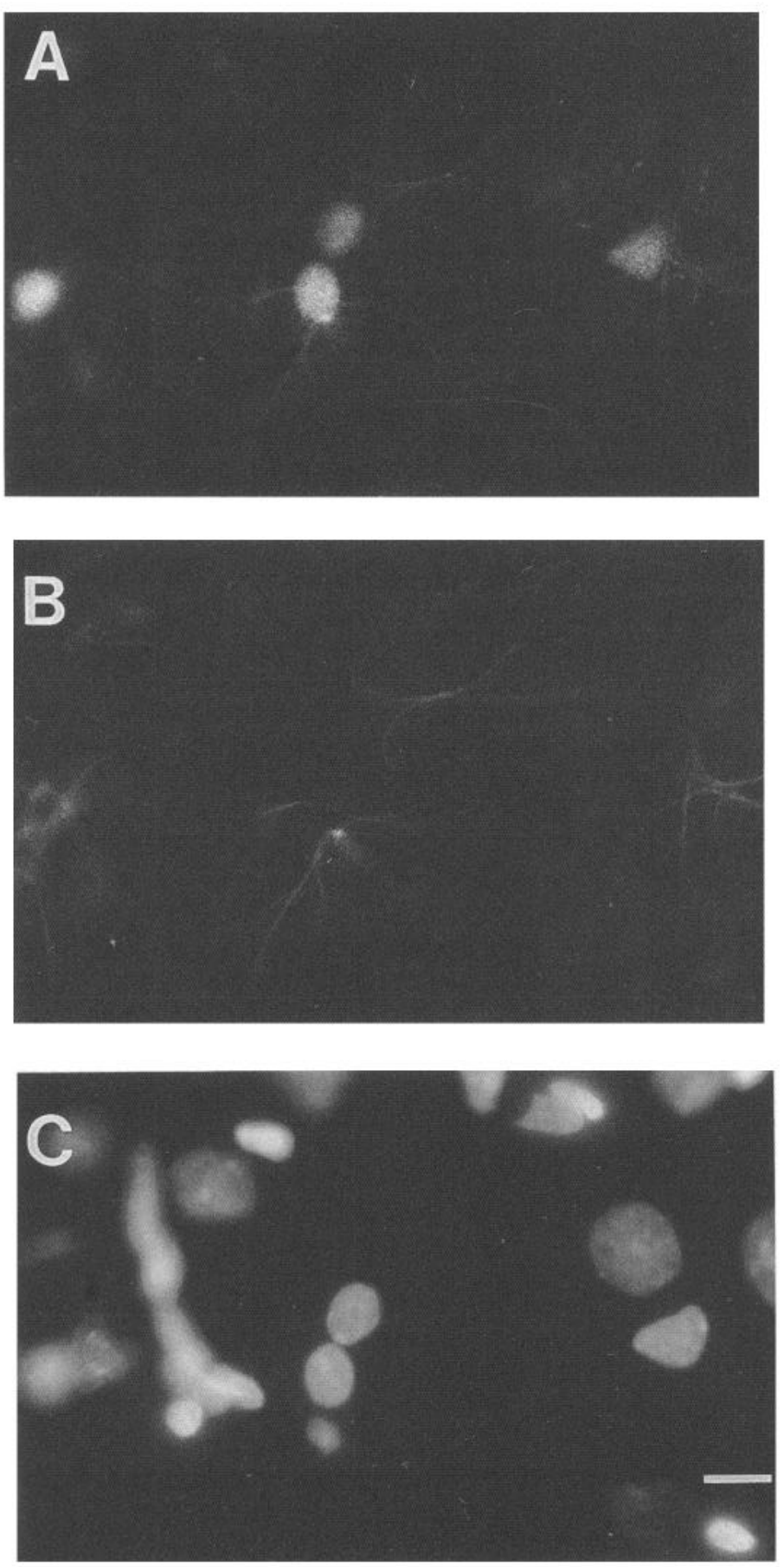

Figure 2. Double immunofluorescent localization of bFGF and GFAP immunoreactivity, with simultaneous fluorescent localization of DNA in nuclei. A section through adult entorhinal cortex is shown, which was stained simultaneously with mouse monoclonal antibody to bFGF and a polyclonal rabbit antiserum to GFAP, followed by incubation with fluorescein-labeled anti-mouse and rhodamine-labeled anti-rabbit antibodies and Hoechst dye 33528 (to stain nuclei), and viewed with appropriate fluorescence filters (see Materials and Methods for details). $A$, bFGF immunoreactivity; $B$, GFAP immunoreactivity; $C$, Hoechst stain of nuclei. Note that $\mathrm{bFGF}$ and GFAP immunoreactivity is present in the same subpopulation of cells and that the bFGF immunoreactivity is strongest in nuclear regions of labeled cells, whereas GFAP immunoreactivity is largely confined to the processes of these same cells. Scale bar, $8 \mu \mathrm{m}$. were also analyzed for bFGF immunoreactivity. Cultures of cortical astrocytes were found to contain many bFGF-positive cells (Fig. $4 A, B$ ), although the number of bFGF-positive cells was somewhat lower than the number of GFAP-positive cells. In contrast, virtually all GFAP-positive cells in vivo appeared to contain bFGF immunoreactivity (Table 2). In addition, the bFGF staining of astrocytes in culture was largely restricted to the nucleus, where it was clearly most intense in what appeared to be the nucleolus; very little bFGF immunoreactivity was observed in the cytoplasm of cultured astrocytes. The differences in localization of bFGF immunoreactivity between astrocytes in culture and in vivo may be due to a number of reasons: limits of the sensitivity of the staining technique in culture, differences in fixation of cells in culture versus in vivo, and differences in the environment of cells grown in vitro. In good agreement with observations in vivo, cultures highly enriched in cortical neurons contained only a very few distinctly bFGF-positive cells (Fig. $4 C, D)$, which were most likely to be an occasional astrocyte.

Analysis of bFGF activity. We sought to confirm the immunohistochemical localization of bFGF reported here by using an independent measure of the amount of bFGF present in the cells and tissues investigated. bFGF is a mitogen for AKR-2B cells in culture, and the total amount of mitogenic activity present in extracts can be determined by measuring the stimulation of ${ }^{3} \mathrm{H}$-thymidine incorporation into the DNA of these cells (Shipley, 1986; Eckenstein et al., 1991a). This assay alone, however, cannot differentiate between bFGF and other mitogenic growth factors such as epidermal growth factor. Thus, the percentage of total mitogenic activity due to bFGF was determined by comparing total mitogenic activity with that remaining after bFGF had been removed from these extracts by indirect immunoprecipitation. The results of this assay confirmed all the results obtained by immunohistochemical localization of bFGF, in that (1) bFGF levels were highest in enriched cultures of cortical astrocytes and very low in cultures of cortical neurons; (2) significant levels of bFGF were observed in mature cerebral cortex, while levels were low in newborn cortex; and (3) both nuclear and soluble fractions of adult rat CNS contained bFGF (Table 2).

It is not surprising that pure cultures of astrocytes contained higher levels of bFGF per milligram of protein than mature cerebral cortex which contains many cell types, of which only astrocytes appear to contain detectable amounts of bFGF.

Since detergent ( $1 \%$ CHAPS) was used in the preparation of the nuclear fraction, the soluble fraction undoubtedly contained cytoplasmic as well as membrane-associated molecules. Extraction of tissues without detergent results in the solubilization of similar amounts of mitogenic activity (Eckenstein et al., 1991a); thus, the majority of bFGF in the solubilized fraction very likely is of cytoplasmic origin. The nuclear fraction contained more than $75 \%$ of the total DNA, as determined by a fluorometric assay, and the ratio of DNA to protein was greater than eightfold higher in the nuclear fraction than in the starting homogenate. Microscopic analysis confirmed this enrichment of nuclei in the nuclear fraction (Fig. 5).

Western blot analysis of $b F G F$. Recent reports indicate the existence of at least three different molecular weight forms of bFGF, possibly resulting from differential initiation of translation (Florkiewicz and Sommer, 1989; Renko et al., 1990; Bugler et al., 1991). Therefore, it was of interest to determine whether these forms were expressed in the cultured cells and tissues of rat CNS analyzed here. Western blot experiments, 

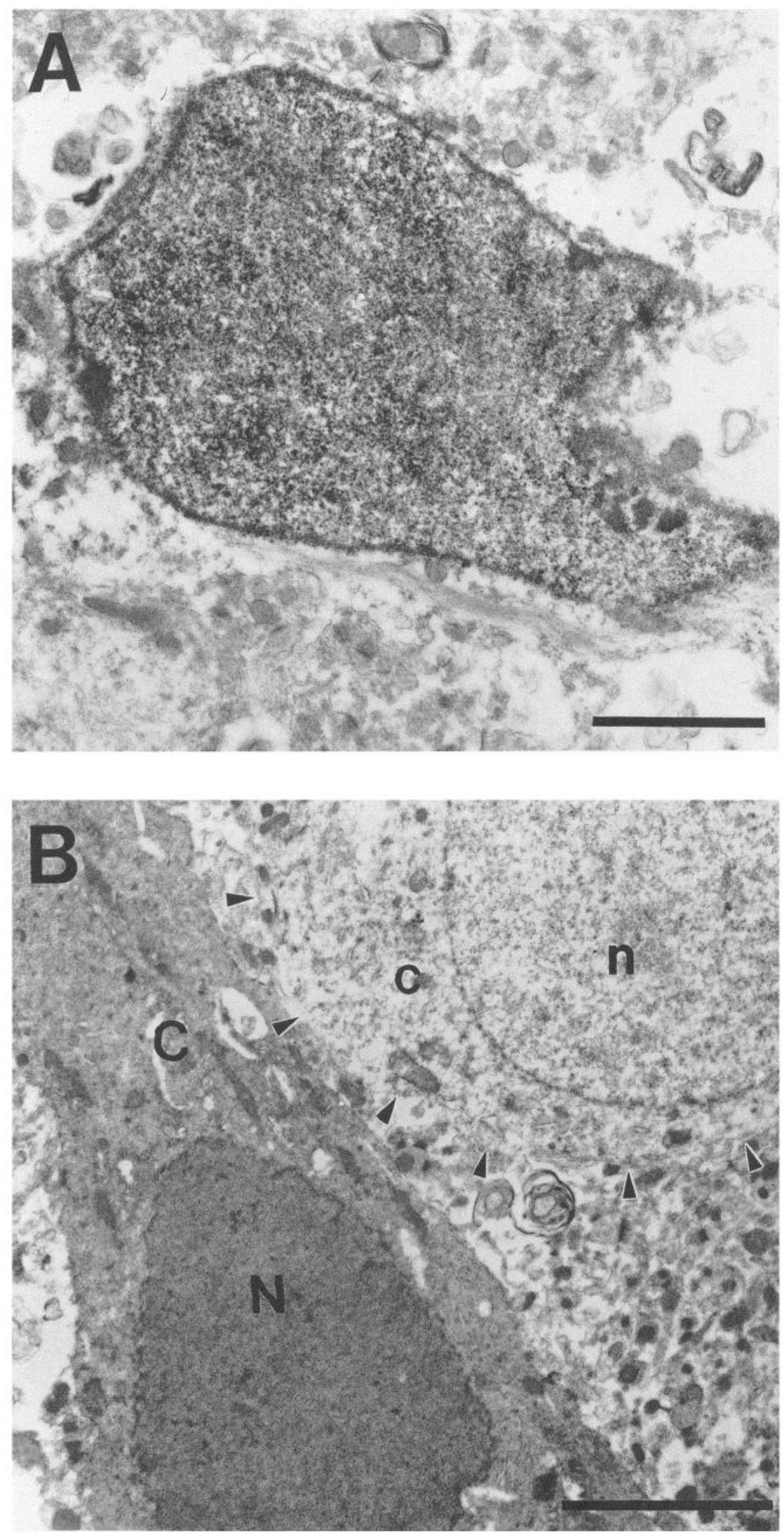

Figure 3. EM localization of bFGF immunoreactivity in the CA2 area of adult hippocampus. $A$, Intense staining is found in the nucleus of an astrocyte, as identified by the presence of glial filaments. Astrocytic cytoplasm is difficult to observe, due to the mild fixation conditions used to preserve bFGF immunoreactivity. $B$, Strong staining is also seen in the nucleus $(N)$ of a labeled CA2 neuron, but distinct staining can also be seen in the cytoplasm $(C)$ of this cell. An adjacent neuron shows no staining in either the nucleus $(n)$ or the cytoplasm (c); arrowheads delineate the cell boundary of the unstained neuron. Note the irregular shape of the nucleus in the stained neuron and the round, regular shape of the nucleus in the unstained neuron. This irregularity of nuclear shape was typical for the great majority of stained CA2 neurons, whereas the majority of unstained neurons showed more regular nuclear morphology. Scale bars: $A, 3.5 \mu \mathrm{m} ; B, 5 \mu \mathrm{m}$. 

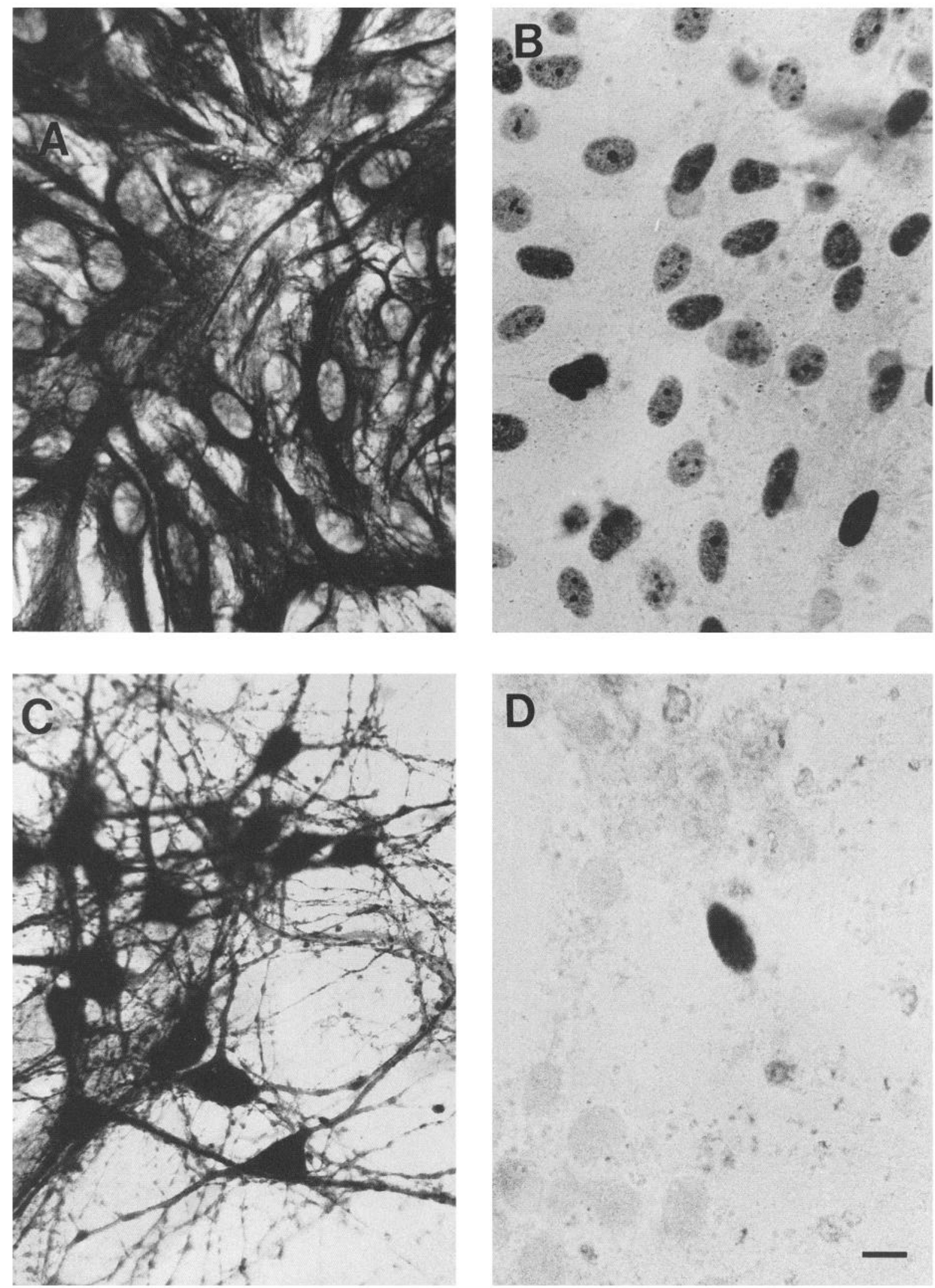

Figure 4. Immunoperoxidase localization of GFAP, neurofilament, and bFGF in cultured cortical astrocytes and neurons. $A$, The vast majority of cells in the astrocyte culture are GFAP positive. $B$, Most, but not all, astrocytes in a sister culture contain bFGF immunoreactivity. The bFGF staining appears to be localized mostly to the nucleus and nucleolus of stained astrocytes. $C$, The majority of cells in neuronal cultures contain neurofilament immunoreactivity. $D$, Only very rarely is a bFGF-positive cell observed in neuronal sister cultures. This staining also appears mostly nuclear and is found exclusively in large cells with a morphology indicative of astrocytes that are present in low numbers in these neuronal cultures (see also Table 2). Scale bar, $8 \mu \mathrm{m}$. 

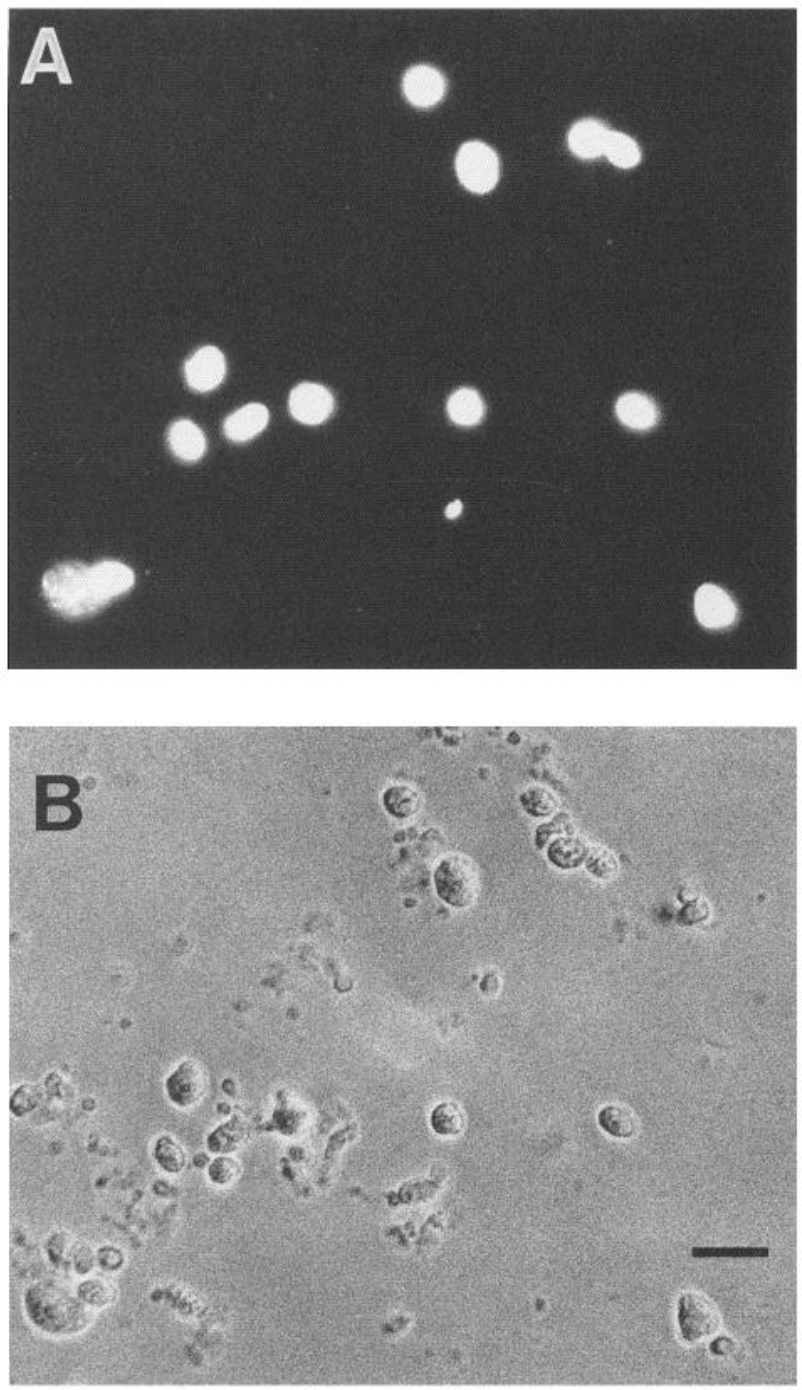

Figure 5. Fluorescent and phase microscopic inspection of nuclear preparations from adult forebrain. Nuclei were prepared and stained with Hoechst dye 33528 as described in Materials and Methods. A, Nuclei, identified by their strong fluorescence following dye binding, constitute the majority of material in such preparations. $B$, Additional contaminating nonfluorescent material, however, is detected by phasecontrast microscopy. Scale bar, $12 \mu \mathrm{m}$.

using the same monoclonal antibody to bFGF employed for immunohistochemistry, were performed to investigate this possibility (Fig. 6). Adult rat cerebral forebrain and cultured astrocytes expressed all three forms of bFGF (18 kDa, $21.5 \mathrm{kDa}$, and $22.5 \mathrm{kDa}$ in molecular mass) in similar abundance. All three forms were also present in soluble fractions prepared from adult rat CNS, whereas nuclear fractions contained nearly exclusively the $21.5 \mathrm{kDa}$ and $22.5 \mathrm{kDa}$ forms. In agreement with results described above, cultured cortical neurons did not contain detectable amounts of any of these forms of bFGF.

\section{Discussion}

As a step toward better understanding the physiological function of FGFs in the nervous system, we investigated the cellular and intracellular distribution of bFGF in the rat CNS. We found that bFGF immunoreactivity was present primarily in astrocytes throughout the CNS as well as in a few identified neuronal

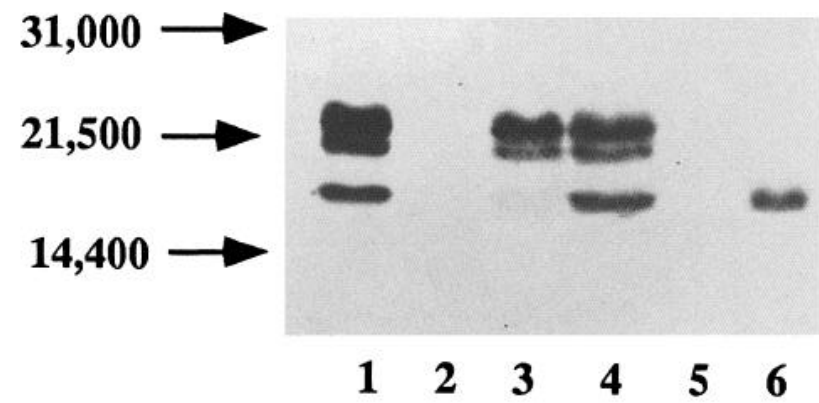

Figure 6. Specific detection of bFGF by Western blot. Different cell and tissue extracts were prepurified using heparin-Affigel and processed for Western blot detection of bFGF immunoreactivity as described in Materials and Methods. Three bands of slightly different molecular mass $(18 \mathrm{kDa}, 21.5 \mathrm{kDa}$, and $22.5 \mathrm{kDa})$ of bFGF immunoreactivity are seen in extracts prepared from cultured astrocytes (lane 1, $2 \mathrm{mg}$ starting protein), but no detectable bFGF bands are present in extracts from cultured neurons (lane 2, $4 \mathrm{mg}$ starting protein). Nuclear preparations from forebrain contain only the two higher molecular weight forms of bFGF immunoreactivity (lane 3, $2 \mathrm{mg}$ starting protein), whereas soluble fractions from forebrain contain all three forms (lane $4,10 \mathrm{mg}$ starting protein). The specificity of the monoclonal antibody to bFGF used is demonstrated by the fact that $200 \mathrm{ng}$ of human recombinant aFGF (lane 5 ) are not stained, whereas $1 \mathrm{ng}$ of human recombinant $18 \mathrm{kDa}$ bFGF results in a strongly labeled band (lane 6). Numbers on the left indicate molecular weight.

populations, including pyramidal neurons in the CA2 region of hippocampus and neurons in the retrosplenial cortex. That bFGF is localized in adult CNS mainly to astrocytes was confirmed by two other observations: (1) highly enriched cultures of astrocytes, confirming an earlier report (Ferrara et al., 1988; these authors, in addition, demonstrated the expression of bFGF mRNA in cultured astrocytes), contained high levels of bFGF immunoreactivity and bioactivity, whereas highly enriched cultures of cerebral cortical neurons contained no detectable bFGF; and (2) neonatal rat cerebral cortex, which contains few differentiated astrocytes, also had no detectable bFGF immunoreactivity and only low amounts of mitogenic activity. Interestingly, bFGF immunoreactivity was found in the nucleus as well as in the cytoplasm of labeled cells.

These results are in conflict with previous immunohistochemical studies of the distribution of bFGF that had indicated a much more widespread neuronal localization of bFGF (Pettmann et al., 1986; Finklestein et al., 1988; Janet et al., 1988). Our results, however, are in good agreement with a recent report describing the distribution of bFGF mRNA by in situ hybridization, including the demonstration of specific expression of bFGF mRNA by hippocampal CA2 neurons (Emoto et al., 1989). Moreover, the present observations are consistent with our earlier findings that bFGF bioactivity is distributed relatively evenly throughout the CNS and is present in stumps of transected optic nerve that lack axons and hence contain only glia (Eckenstein et al., 1991a). The differences in immunohistochemical localization of bFGF in the nervous system described here and those reported previously may be due to differences in the source of antibodies; the present study used a monoclonal antibody to bFGF that appears to be monospecific for bFGF (Eckenstein et al., 1991a), whereas previous studies reporting widespread localization of bFGF to all neurons in CNS utilized polyclonal antibodies that, because of the significant sequence homology among the seven members of the FGF family, may have crossreacted with FGFs not recognized by the monoclonal antibody 
Table 2. Levels of bFGF bioactivity in tissues and cell cultures

\begin{tabular}{llllll} 
& $\begin{array}{l}\text { Mitogenic } \\
\text { units/mg } \\
\text { protein } \\
\text { control } \\
\text { antibody }\end{array}$ & $\begin{array}{l}\text { Mitogenic } \\
\text { units/mg } \\
\text { protein }+ \\
\text { antibody } \\
\text { to bFGF }\end{array}$ & $\begin{array}{l}\text { Mitogenic } \\
\text { units of } \\
\text { bFGF per } \\
\text { mg protein }\end{array}$ & $\begin{array}{l}\text { Number of } \\
\text { GFAP- } \\
\text { positive } \\
\text { cells }\end{array}$ & $\begin{array}{l}\text { Number of } \\
\text { bFGF- } \\
\text { positive } \\
\text { cells }\end{array}$ \\
\hline $\begin{array}{l}\text { Adult cerebral cortex } \\
\text { Newborn cerebral cortex }\end{array}$ & 27.5 & 10.5 & 16.0 & 43.7 & 46.1 \\
$\begin{array}{l}\text { Nuclear extract from adult } \\
\text { forebrain }\end{array}$ & 3.3 & $<2.0$ & $<3.3$ & 1.1 & 0 \\
$\begin{array}{l}\text { Soluble extract from adult } \\
\text { forebrain }\end{array}$ & 89.3 & 33.3 & 56.0 & $\mathrm{ND}$ & $\mathrm{ND}$ \\
$\begin{array}{l}\text { Cortical astrocytes } \text { in vitro } \\
\begin{array}{l}\text { Cortical neurons } \text { in vitro } \\
\text { bFGF (100 ng/mg of }\end{array}\end{array}$ & 23.8 & 8.2 & 15.6 & $\mathrm{ND}$ & $\mathrm{ND}$ \\
$\quad$ carrier protein) & $<2.0$ & $<2.0$ & 48.5 & 39.4 & 28.8 \\
\end{tabular}

The amount of bFGF activity was quantificd by determining the amount of mitogenic activity precipitated by a monoclonal antibody to bFGF (see Materials and Methods for details; SE did not exceed $\pm 20 \%$ of total values). The number of GFAP- and bFGF-positive cells is the mean number of stained cells observed in 10 fields of view of equal size (SE did not exceed $\pm 20 \%$ of total values). Note that the levels of bFGF activity correlate well with the presence of GFAPpositive astrocytes, and that bFGF-activity is present in both soluble and nuclear extracts of forebrain. ND, Not determined.

used here. These other members of the FGF family may be more highly concentrated in neurons than bFGF. This would be consistent with our previously published results suggesting that aFGF is found in some classes of peripheral neurons (Eckenstein et al., 1991a,b). On the other hand, if these other members of the FGF family are mitogens like bFGF, then we should not have found such an excellent correlation of mitogenic activity with bFGF immunoreactivity in the CNS. Perhaps these other FGFs had no effect on the AKR-2B cells used for our biological assay, where aFGF, for example, is inactive in the absence of heparin (Eckenstein et al., 1991a). Clearly, additional studies with probes for other FGFs are needed to describe fully the distribution of FGFs in the CNS.

In general, polypeptide growth factors are expected to be made available to the cells that respond to them by secretion; thus, their intracellular distribution would be expected to be within the rough endoplasmic reticulum, the Golgi apparatus, and secretory granules (Walter and Lingappa, 1986). We have found that bFGF in astrocytes and CA2 neurons differed from this expectation in that significant amounts of bFGF immunoreactivity and bioactivity were present both in the nucleus and in the cytoplasm. Three bands of bFGF immunoreactivity of slightly different molecular masses (18 kDa, $21.5 \mathrm{kDa}$, and $22.5 \mathrm{kDa}$ ) were identified in Western blots of soluble fractions prepared from CNS, whereas only the two higher molecular mass bands were present in nuclear fractions. These observations agree well with earlier studies demonstrating a similar pattern of distribution of the different forms of bFGF in the nucleus versus the cytoplasm in cells that were transfected in vitro with bFGF expression DNA vectors (Renko et al., 1990). It should be noted that all three forms of bFGF appear to have similar mitogenic activity when added to fibroblasts in culture (Florkiewicz and Sommer, 1989).

Since bFGF lacks the traditional hydrophobic signal peptide sequence (Burgess and Maciag, 1989) that appears to be needed to target polypeptides into the secretory pathway (Walter and Lingappa, 1986), our observation of intracellular localization of bFGF was not unexpected. This result appears to conflict with a previous report that at least a small amount of bFGF may be present on the surface of cultured astrocytes because fiber outgrowth of cerebellar granule cells on astrocytes in vitro has been reported to be blocked by the addition to the culture medium of antibodies of bFGF (Hatten et al., 1988). This extracellular bFGF, however, may have been the result of cell lysis or release by an unconventional mechanism such as intracellular binding of bFGF to carrier proteoglycans that may subsequently be released (Gordon et al., 1989). Our own preliminary results indicate that although astrocytes in vitro contain significant stores of bFGF, little bFGF is present in medium conditioned by astrocytes, supporting the notion that bFGF is not efficiently released from intact cells.

The nuclear localization of bFGF was somewhat unexpected, but recent studies have shown that aFGF possesses a nuclear translocation sequence (Imamura et al., 1990). Although the nuclear translocation sequence of aFGF is not essential for the binding to cell surface FGF receptors, it is necessary for the mitogenic effect (Imamura et al., 1990). Observations that bFGF appears to be localized to the nucleus and especially the nucleolus at specific stages of the cell cycle (Baldin et al., 1990) might explain why in the present study the vast majority of astrocytes in vivo (which are likely to be arrested at the same stage of the cell cycle) contained bFGF immunoreactivity in the nucleus, whereas only about $70 \%$ of astrocytes in vitro (which are dividing and not synchronized in their cell cycle) contained nuclear bFGF. A recent study suggests that the presence of bFGF in the nucleus increases the synthesis of mRNA coding for specific ribosomal proteins (Amalric, 1991), and it may be of interest in this respect that specific inhibition of bFGF synthesis by bFGF antisense oligonucleotides in cultured glioma cells significantly reduced the rate of growth of these cells (Morrison, 1991).

These data, taken together with observations that FGF receptors are expressed widely throughout the nervous system (Heuer et al., 1990; Wanaka et al., 1990), allow the formulation of a working hypothesis as to the possible functions of bFGF in the CNS; that is, an important role for bFGF may be to mediate interactions of astrocytes with their environment in 
order to regulate maturation and maintenance of the CNS. This overall function can be subdivided into distinct intra- versus intercellular functions of bFGF. Intracellular functions may include regulating the growth and differentiation of astrocytes and CA2 and retrosplenial neurons by a mechanism that does not involve release but instead involves translocation of newly synthesized bFGF to the nucleus. Possible intercellular functions of $\mathrm{bFGF}$, such as promotion of mitogenesis in a variety of nonneuronal cell types and neurotrophic effects in a variety of neuronal cell types, may be mediated by bFGF released from astrocytes and acting extracellularly by binding to FGF receptors on the plasma membrane (Hatten et al., 1988). This extracellular bFGF may include low levels of bFGF released by unconventional mechanisms in normal CNS tissue, and larger amounts of bFGF released from intracellular stores during cell lysis after injury. Interestingly, the intracellular translocation of the FGF signal after binding to the surface receptor may also involve transport to the nucleus (Baldin et al., 1990). Thus, the intraand intercellular functions of FGFs may involve similar pathways in the nucleus. Clearly, future studies are needed to test the prediction of two separate signaling pathways for FGF proposed by this working hypothesis.

\section{References}

Amalric F (1991) Nuclear translocation of basic fibroblast growth factor. In: The fibroblast growth factor family (Baird A, Klagsbrun M, eds). New York: New York Academy of Sciences, in press.

Baldin V, Roman A, Bosc-Bierne I, Amalric F, Bouche G (1990) Translocation of bFGF to the nucleus is G1 phase cell cycle specific in bovine aortic endothelial cells. EMBO J 9:1511-1517.

Bottenstein JE, Sato GH (1979) Growth of a rat neuroblastoma cell line in serum free supplemented medium. Proc Natl Acad Sci USA 76:514-517.

Bugler B, Amalric F, Prats H (1991) Alternative initiation of translation determines cytoplasmic or nuclear localization of basic fibroblast growth factor. Mol Cell Biol 11:573-577.

Burgess WH, Maciag T (1989) The heparin-binding (fibroblast) growth factor family of proteins. Annu Rev Biochem 58:575-606.

Davis JB, Stroobant P (1990) Platelet-derived growth factors and fibroblast growth factors are mitogens for rat Schwann cells. J Cell Biol 110:1353-1360.

Eccleston PA, Silberberg DH (1985) Fibroblast growth factor is a mitogen for oligodendrocytes in vitro. Brain Res 353:315-318.

Eckenstein FP, Esch F, Holbert T, Blacher RW, Nishi R (1990) Purification and characterization of a trophic factor for embryonic peripheral neurons: comparison with fibroblast growth factors. Neuron 4:623-631.

Eckenstein FP, Shipley GD, Nishi R (1991a) Acidic and basic fibroblast growth factors in the nervous system: distribution and differential alteration of levels after injury of central versus peripheral nerve. J Neurosci 11:412-419.

Eckenstein F, Woodward W, Nishi R (1991b) Differential localization and possible functions of aFGF and bFGF in the central and peripheral nervous system. In: The fibroblast growth factor family (Baird A, Klagsbrun M, eds). New York: New York Academy of Sciences, in press.

Emoto N, Gonzalez A-M, Walicke PA, Wada E, Simmons DM, Shimasaki S, Baird A (1989) Basic fibroblast growth factor (FGF) in the central nervous system: identification of specific loci of basic FGF expression in the rat brain. Growth Factors 2:21-29.

Ferrara N, Ousley F, Gospodarowicz D (1988) Bovine brain astrocytes express basic fibroblast growth factor, a neurotropic and angiogenic mitogen. Brain Res 462:223-232.

Finklestein SP, Apostolides PJ, Caday CG, Prosser J, Philips MF, Klagsbrun M (1988) Increased basic fibroblast growth factor (bFGF) immunoreactivity at the site of focal brain wounds. Brain Res 460:253259.

Florkiewicz RZ, Sommer A (1989) Human basic fibroblast growth factor gene encodes four polypeptides: three initiate translation from non-AUG codons. Proc Natl Acad Sci USA 86:3978-3981.
Gordon PB, Choi HU, Conn G, Ahmed A, Ehrman B, Rosenberg L, Hatcher VB (1989) Extracellular matrix heparin sulfate proteoglycans modulate the mitogenic capacity of acidic fibroblast growth factor. J Cell Physiol 140:584-592.

Gospodarowicz D, Ferrara N, Schweigerer L, Neufeld G (1987) Structural characterization and biological functions of fibroblast growth factor. Endocr Rev 8:95-1 14.

Grothe C, Otto D, Unsicker K (1989) Basic fibroblast growth factor promotes in vitro survival and cholinergic development of rat septal neurons: comparison with the effects of nerve growth factor. Neuroscience 31:649-661.

Hatten ME, Lynch M, Rydel RE, Sanchez J, Joseph SJ, Moscatelli D, Rifkin DB (1988) In vitro neurite extension by granule neurons is dependent upon astroglial-derived fibroblast growth factor. Dev Biol 125:280-289.

Heuer JG, von Bartheld CS, Kinoshita Y, Evers PC, Bothwell M (1990) Alternating phases of FGF receptor and NGF receptor expression in the developing chicken nervous system. Neuron 5:283-296.

Heuttner JE, Baughman RW (1986) Primary culture of identified neurons from the visual cortex of postnatal rats. J Neurosci 6:3044-3060.

Imamura $T$, Engleka $K$, Zhan X, Tokita $Y$, Forough R, Rocder D, Jackson A, Maier J, Hla T, Maciag T (1990) Recovery of mitogenic activity of a growth factor mutant with a nuclear translocation sequence. Science 249:1567-1570.

Janet T, Grothe C, Pettmann B, Unsicker K, Sensenbrenner M (1988) Immunocytochemical demonstration of fibroblast growth factor in cultured chick and rat neurons. J Neurosci Res 19:195-201.

Labarca C, Paigen K (1980) A simple, rapid, and sensitive DNA assay procedure. Anal Biochem 102:344-352.

Lipton SA, Wagner JA, Madison RD, D'Amore PA (1988) Acidic fibroblast growth factor enhances regeneration of processes by postnatal mammalian retinal ganglion cells in culture. Proc Natl Acad Sci USA 85:2388-2392.

Marchese C, Rubin J, Ron D, Faggioni A, Torrisi R, Messina A, Frati L, Aaronson SA (1990) IIuman keratinocyte growth factor activity on proliferation and differentiation of human keratinocytes: differentiation response distinguishes KGF from EGF family. J Cell Physiol 144:326-332.

Marics I, Adelaide J, Raybaud F, Mattei M-G, Coulier F, Planche J, De Lapeyriere O, Birnbaum D (1989) Characterization of the HSTrelated FGF. 6 gene, a new member of the fibroblast growth fractor gene family. Oncogene 4:335-340.

McCarthy KD, de Vellis J (1980) Preparation of separate astroglial and oligodendroglial cell cultures from rat cerebral tissue. J Cell Biol 85:890-902.

Moore R, Casey G, Brookes S, Dixon M, Peters G, Dickson C (1986) Sequence, topography and protein coding potential of mouse int-2: a putative oncogene activated by mouse mammary tumour virus. EMBO J 5:919-924.

Morrison RS (1991) Suppression of basic fibroblast growth factor expression by antisense oligodeoxynucleotides inhibits the growth of transformed human astrocytes. J Biol Chem 266:728-734.

Morrison RS, Rharma A, deVellis J, Bradshaw RA (1986) Basic fibroblast growth factor supports the survival of cerebral cortical neurons in primary culture. Proc Natl Acad Sci USA 83:7537-7541.

Pettmann B, Weibel M, Sensenbrenner M, Labourdette G (1985) Purification of two astroglial growth factors from bovine brain. FEBS Lett 189:102-108.

Pettmann B, Labourdette G, Weibel M, Sensenbrenner M (1986) The brain fibroblast growth factor (FGF) is localized in neurons. Neurosci Lett 68:175-180.

Renko M, Qurto N, Morimoto T, Rifkin DB (1990) Nuclear and cytoplasmic localization of different basic fibroblast growth factor species. J Cell Physiol 44:108-114.

Schubert D, Ling N, Baird A (1987) Multiple influences of a heparinbinding growth factor on neuronal development. J Cell Biol 104:635643.

Shipley GD (1986) A serum-free $\left[{ }^{3} \mathrm{H}\right]$ thymidine incorporation assay for the detection of transforming growth factors. J Tissue Cult Methods 10:117-123.

Shipley GD, Ham RG (1981) Improved medium and culture conditions for clonal growth with minimal serum protein and for enhanced serum-free survival of Swiss 3T3 cells. In Vitro 17:656-670.

Stemple DL, Mahanthappa NK, Anderson DJ (1988) Basic FGF induces neuronal differentiation, cell divison, and NGF dependence in 
chromaffin cells: a sequence of events in sympathetic development. Neuron 1:517-525.

Taira M, Yoshida T, Miyagawa K, Sakamoto H, Terada M, Sugimura $T$ (1987) cDNA sequence of human transforming gene HST and identification of the coding sequence required for transforming activity. Proc Natl Acad Sci USA 84:2980-2984.

Thomas KA (1987) Fibroblast growth factors. FASEB J 1:434-440.

Unsicker K, Reichert-Preibsh H, Schmidt R, Pettmann B, Labourdette G, Sensenbrenner M (1987) Astroglial and fibroblast growth factors have neurotrophic functions for cultured peripheral and central nervous system neurons. Proc Natl Acad Sci USA 84:5459-5463.

Wagner JA, D'Amore PA (1986) Neurite outgrowth induced by an endothelial cell mitogen isolated from retina. J Cell Biol 103:13631367.

Walicke P, Cowan WM, Ueno N, Baird A, Guillemin R (1986) Fi- broblast growth factor promotes survival of dissociated hippocampal neurons and enhances neurite extension. Proc Natl Acad Sci USA 83:3012-3016.

Walter P, Lingappa VR (1986) Mechanisms of protein translocation across the endoplasmic reticulum membrane. Annu Rev Cell Biol 2: 499-516.

Wanaka A, Johnson EM, Milbrandt J (1990) Localization of FGF receptor mRNA in the adult rat central nervous system by in situ hybridization. Neuron 5:267-281.

Wood JN, Anderton BH (1981) Monoclonal antibodies to mammalian neurofilaments. Biosci Rep 1:263-268.

Zhan X, Bates B, Hu XG, Goldfarb M (1988) The human FGF-5 oncogene encodes a novel protein related to fibroblast growth factors. Mol Cell Biol 8:3487-3495. 